\title{
Developing Emotionally Intelligent Teachers: A Panacea for Quality Teacher Education
}

\author{
Gloria Matthews Ph.D ${ }^{1}$ \\ ${ }^{1}$ Department of Educational Psychology, Guidance and Counseling \\ Ignatius Ajuru University of Education \\ Rumuolumeni, Port Harcourt \\ Rivers State \\ Nigeria
}

\begin{abstract}
Psychologist and Researchers have established that emotional intelligence influence students' academic achievement, self-efficacy, emotional regulation and motivation. However, in most teachers training institutions in Nigeria there are no facilities and program put in place to teach emotional intelligence skill. A classroom comprise of students from various socio-economic background with different personalities, these students express positive and negative emotions such as happiness, anger, distress and excitement which could influence learning. In the light of this situation, it becomes imperative for teacher educators and administrators of teachers' training collages to develop emotionally intelligent teachers who have the capacity to regulate their emotions accurately and understand the emotions of students in their various classrooms. This is necessary to assist students become emotionally stable and facilitates the teaching-learning process. Consequently, the paper seeks to examine the concept of emotional intelligence, concept of quality education, concept of teacher education, theories of emotional intelligence and the relevance of training emotionally intelligent teachers for quality teacher education. Finally, the paper recommend amongst others, the inclusion of emotional intelligence skill in the curriculum of teachers training institutions.
\end{abstract}

Keywords: Emotional Intelligence, Quality Education, Teacher Education.

\section{INTRODUCTION}

Education in all human society, is regarded as the vehicle used for transmission of skills, knowledge, values, attitude and information from one generation to the next. It involves the process of a teacher imparting knowledge, skills, values and attitude to another group of relatively inexperienced people. Fafunwa (2004) described Education as a medium that help the Individual to develop qualities, attitudes and skills that have positive impact on society. Effective transmission of knowledge, require an emotional intelligent teacher that has the capacity to understand and regulate his/her emotions and that of students, this is based on the premise that an individual emotional state influence learning either positively or negatively (Matthews 2014). Several researches conducted have indicated the importance of emotional intelligence in achieving success in academics, motivations, self-awareness, empathy and social competence therefore, teachers education institutions need to produce teachers who are behaviorally, socially, intellectually and emotionally balanced in-order to achieve quality education.

Emotions play a major role in the teaching-learning process, it also influences the cognitive processes in human, which include reasoning, attention, judgment and perception. Furthermore, emotions determine how information is processed in the memory; a student that is emotionally unstable may find it difficult to process information. The classroom encompasses various emotional states such as distress, anger, excitement, joy and disgust, including subjective feelings that could interfere with learning. Hence, training teachers to develop emotional intelligence skills should be given due consideration by teacher educators. However, the reality on ground is that most teachers lack emotional intelligence skills, they are low on self-awareness, motivation, empathy and social skills which are all elements of emotional intelligence. Furthermore, it has been established that emotions drive attention, for example a student that is angry about an incident at home will find it difficult to pay attention during learning, it takes an emotionally intelligent who understands others emotions to respond accurately to the child's needs. However, most teacher educators pay little attention to teachers' emotional intelligence as opposed to cognitive intelligence.

The emphasis on learning without character development is the foundation of students' maladaptive behavior, according to Boyatzis (2008) students can be trained to become emotionally intelligent. In the same vein, professionals like teachers also require emotional intelligence competencies (Singh 2003). The period of adolescence is characterized by emotional instability, This critical stage of development coincide with the schooling age, most students lack the capacity to regulate their emotions, this situation has led students to commit suicide, depressed and psychologically disorganized as such, an emotionally 
intelligent teacher that have the ability to teach these adolescents how to regulate their emotions, cope with stress and render counseling services is required. Teachers are the drivers of the educational system, their job require interacting with students with individual differences and varied emotional expressions, the ability to regulate and interpret these emotions accurately is critical for academic achievement. The point to note is that students who are emotionally unstable cannot benefit from learning experiences.

In the same vein, Goleman (2008) defined emotional intelligence as the ability to understand one's emotion and that of others in order to appropriately interpret these emotions and to direct human behavior, this implies that an individual emotional state play an important role in guiding and directing human behavior. In spite of the critical role played by emotional intelligence, the concept of emotional intelligence has remained an enigma to most teachers; some teachers do not have an in-depth understanding about the concept of emotional intelligence neither emotional intelligence competencies.

The above situation could be based on the premise that teachers training colleges are not producing emotionally intelligent teachers. Consequently, the paper calls for inclusion of emotional intelligence skill as a course of study in teachers training colleges for quality education.

\section{THE CONCEPT OF EMOTIONAL INTELLIGENCE}

Emotional Intelligence was conceptualized by Peter Salovey and John Mayer while Daniel Goleman popularized the concept of emotional intelligence through publications of articles, books and journals. Emotional intelligence is focused on how an individual could have accurate knowledge and understanding of his emotions, regulate his emotions, being empathetic about others emotions also assisting others to manage their emotions effectively. Salovey, Mayer and Caruso (2004) defined emotional intelligence as the ability to understand emotional information and apply it to social environment. This implies that there is need for teachers to acquire emotional intelligence competences and apply such knowledge to students in the classroom setting which form part of the social environment.

Goleman (1998) defined emotional intelligence as the ability to adjust one's emotions in order to adapt to one's environment. From this definition we can deduce that emotional intelligence is required to cope and manage with the demands of one's environment. Academic achievement depends on character and learning, students and teachers are expected to acquire emotional intelligence competences in order to achieve quality education. Berges and Augusto (2007) defined emotional intelligence as the ability to perceive and manage one's emotion and that of others, this implies that it is appropriate for teacher educators to equip teachers in training with skills on how to manage their emotions and that of others, In a typical classroom setting, there are some students that are disobedient, hyperactive and distressed. A teacher with knowledge of emotional intelligence is required to manage and direct their behavior appropriately for quality education.

Similarly, Coleman (2003) defined emotional intelligence as the ability to monitor one's emotion and that of others to discriminate between different emotions and label them appropriately, in order to use emotional information to guide thinking and behavior. Knowledge acquired from emotional intelligence can be used to monitor and direct human behavior, it can also be used for understanding and management of other's emotion. The concept of emotional intelligence has five key elements which are: selfawareness, self-regulation, social skills, motivation and empathy. All these are essential for molding student's character and cognitive intelligence.

\section{THE CONCEPT OF QUALITY EDUCATION}

Quality Education is an indispensable requirement for sustainable development. There are some that describe quality education based on literacy and numeracy. However, Education is not limited to the aforementioned factors alone, emotional intelligence skill is an essential part of quality education. Acquisition of Emotional intelligence competencies help to develop the learner socially, academically, behaviorally and emotionally. Quality Education is expected to fulfill the needs and expectations of society; it should have the capacity to enhance the capability of the recipients. Quality education encompasses effective teaching and learning process, acquisition of knowledge, emotional intelligence and technical competency. It also focuses on cultivation of skills, trade or profession as well as mental, moral and athletic development (Ezeonwuka and Okanume-Onah 2016). Education is an integral part of social, political, economic and moral development as such teacher's educators are required to acquaint pre-service teachers with emotional intelligence skills for effective teaching- learning at all levels of education. Quality education embodies emotional stability of the learner, motivation, self- awareness and 
effective communication skills, teachers that are emotionally intelligent are trained to identify and regulate students' emotions in-order to facilitate learning.

Unesco and Unicef in maple (2011) viewed quality education in the following ways:

- Quality education refers to the extent in which the educational system meets or responds to the economic needs of the society.

- It refers to the effectiveness with which educational system promote cultural values, morals and attitude of the society.

- It refers to learners' performance or standard of attainment in school subjects. In summary, Quality education is a well-organized training program that requires emotionally intelligent teachers that will aid learners to attain the stated goals and objectives of education, and furthermore, to develop emotionally stable and cognitively intelligent students in-order to meet the demands of the society.

\section{THE CONCEPT OF TEACHER EDUCATION}

Teacher Education refers to policies, procedures and programs designed to equip prospective teachers with relevant and appropriate knowledge, skills, values and competencies that are required to efficiently and effectively execute the task of teaching in the classroom, schools and wider community, (Nwaldo 2015). In the same vein, Oyekan (2006) defined Teacher Education as a professional Education and specialized training within a specified period, for the preparation of individuals who intend to develop and nurture young ones into responsible citizens. This definition implies that teachers are responsible for nurturing young ones into responsible citizens; accomplishing such a task would require an emotionally intelligent teacher that has the ability to regulate one's emotions, moods and feelings, as well as that of the students. Matthews (2014) defined Teacher Education as an aspect of training that is focused on equipping in-service teachers with knowledge, skills and attitude that facilitate teachers' effectiveness in the classroom.

Similarly, the National Council of Teacher Education act defined teacher education as program of education such as research and training that is required to equip prospective teachers with competencies that are needed to function effectively in the classroom and non-school setting. This is based on the premise that, there could be no meaningful discourse about education without considering the quality of the teacher, given this situation; teacher educators are expected to develop programs and skills that will equip pre-service teachers to become emotionally intelligent, to understand and interpret student's emotions and also regulate their emotions effectively.

\section{Goals of Teacher Education in Nigeria 2004 include the following:}

- $\quad$ To produce highly motivated, conscientious and efficient classroom teachers for all levels of educational system.

- $\quad$ Encourage the spirit of enquiry and creativity in teachers.

- Help teachers fit into social life of community and the society at large also enhance their commitment to national goals.

- $\quad$ Provide teachers with the intellectual and professional background adequate for their assignment situation.

- $\quad$ Enhance teachers' commitment to the teaching profession.

Consequently, the objective of teacher education as stipulated above can be achieved, when teachers training colleges develop emotionally intelligent teachers.

\section{THEORY OF EMOTIONAL INTELLIGENCE}

The Mixed Model Theory of Emotional Intelligence.

The mixed model theory was propounded by Daniel Goleman. It is referred to as the mixed model theory because it combines emotional intelligence and other personality traits which include self-awareness, selfregulation, motivation, empathy and social skills. Self-awareness refers to the ability of understanding one's feelings, character and emotions. This is an essential aspect of emotional intelligence; it requires closely monitoring of one's emotions, teachers who are self-aware recognize their strength, weaknesses, feelings, and emotions. Emotional intelligence refers to the ability to recognize and understand one's emotion and how it affects others. There is need to examine what and how we feel, in order to manage our emotions effectively.

The major elements of emotional awareness are:

Emotional awareness: refers to being aware of our feelings and their emotional effect. 
- $\quad$ Self-confidence: refers to having self-worth and being confident in your capabilities.

Self-regulation as a component of emotional intelligence refers to having control over your feelings in order to control your emotion appropriately. The teacher that has the capacity to regulate his/her emotions, knows when to walk away from an emotionally tensed situation. In order to regulate one's emotion effectively the following are required: -

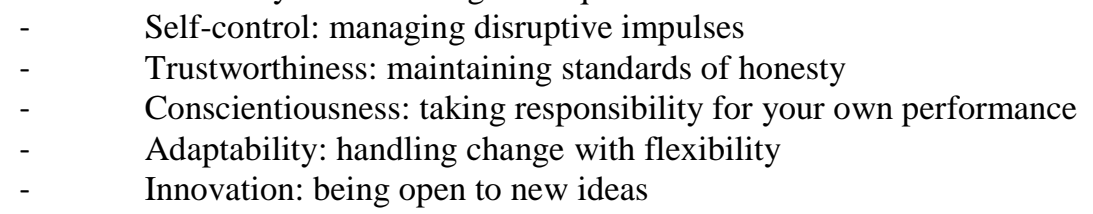

Another component of emotional intelligence is Motivation; it is the push or force that propels an individual towards achievement of a goal. Motivation could be intrinsic and extrinsic. Emotionally intelligent people are motivated to participate in an activity based on interest, aptitude and passion rather than financial benefits, which implies that they are intrinsically motivated. A teacher that is emotionally intelligent has the capacity of assisting students to achieve realistic goals, the concept of motivation is associated with:

- $\quad$ Initiative: taking the lead and making use of opportunities as they are made available.

- $\quad$ Achievement drive: being consistently driven toward one's goal and becoming self-actualized.

- $\quad$ Commitment: aligning with one's values.

- $\quad$ Optimism: being focused on achieving one's goals irrespective of setbacks or disappointments.

Empathy is an essential component of emotional intelligence, this refers to being able to put yourself in another's position in order to feel what they are feeling, perceive things from their own point of view with the hope of providing solution to their problems, furthermore, empathy is an important aspect of the educational process. An empathic teacher is able to understand the feelings and emotions of his or her students and provide the necessary solution to their problems. Emotional intelligence enhances social skill, it is the ability to interact with others, and Social competence requires collaboration, communication, building bonds and conflict management.

\section{A Model of Mixed Theory Model}

Self-Awareness

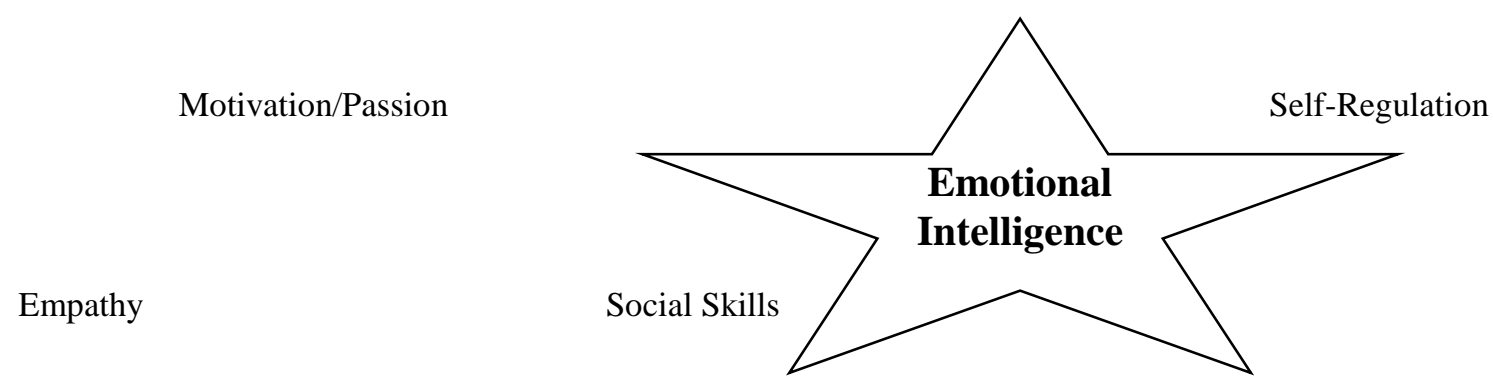

6. DEVELOPING EMOTIONALLY INTELLIGENT TEACHER: A PANACEA FOR QUALITY TEACHER EDUCATION

Quality teacher education refers to education that is pedagogically standardized and enhance the capability of its recipients, by enabling the leaner to become productive members of the society; also assist students to reach their maximum potentials. The sustainable development goal emphasize on inclusive and equitable education that promote life-long learning. Therefore, developing emotionally intelligent teacher is essential to identify and respond to the various emotional needs of students in an inclusive classroom. Teaching is associated with stressors such as poor remuneration, un-conducive learning environment; behavioral problems and individual differences, there are differences in students' socio-economic background, intelligence, numerical ability, personality and aptitude. These differences trigger an array of emotions that require an emotionally intelligent teacher to cope with. Negative emotions such as tension, anger, anxiety interfere with learning and ultimately affect the quality of education; a teacher that is emotionally unstable will lack the patience and tolerance that is required to deal with varied emotions in the classroom. consequently, teacher education Institutions require the inclusion of emotional intelligence skill and programs in their curriculum in order to train teachers to offer quality education that will develop the leaner academically, behaviorally, socially and emotionally. 
Emotional Intelligence refers to the ability to regulate and identify one's emotion and that of others. Salovey and Mayer (1990) defined emotional intelligence as having the capacity to monitor one's emotions selectively and distinguish these emotions from others. It is worthy to note that some components of emotional intelligence are self-awareness, emotional regulation, motivation, empathy and social skills these components facilitate the teaching and learning process.

Self-awareness is an important component of emotional intelligence. Gold and Roth (1993) defined selfawareness as being in touch with one's feeling and behavior, Matthews (2014) defined it as the ability to accurately identify, understand aware and interpret one's emotions. This implies that the individual is in tune with his emotions and can easily walk away from a threatening situation. A teacher that is selfaware is a self-educator, by identifying specific emotions that pose as a threat to his professional and personal growth. Richardson (2001) noted that, self- awareness is essential for teachers who work with students that have emotional and behavioral problems. It can also be referred to as being aware of one's internal state, preference, resources and intensions. Based on the above definitions, one can deduce that teachers' self-awareness leads to being aware of emotions and behavioral patterns that can hinder learning in the classroom, as such the emotional intelligent teachers take proactive measures to regulate such emotions appropriately. In the same vein, they are aware of their psychological histories and personalities that can interfere with learning. In line with the foregoing, it becomes imperative for teacher education institutions to train emotionally intelligent teachers who can adopt various approaches in identifying and engaging students that seem disengaged. Furthermore, Self-awareness is critical for academic achievement, emotionally intelligent teachers modify students emotional and behavioral problems that has the capacity of interfering with learning. Gold and Roth (1993) stated that teachers selfawareness is critical for stress management, academic achievement and provide an in-depth understanding of self and that of others. Research has indicated that student's disruptive behavior and indiscipline in classroom are some of teacher's major concern; emotionally intelligent teachers who are aware about their emotions are better disposed to cope with students behavioral problems effectively.

Another element of emotional intelligence is emotional regulation Sulton (2004) defined emotional regulation as the ability to control one's emotion and facilitate achievement of the individual goals. Similarly, Gross (2002) defined emotional regulation as the ability to control emotional expression and experiences. As earlier stated the classroom is a place where students express various emotions, teachers are constantly faced with circumstances that could trigger anger, frustration, sadness and disgust, these situation require emotionally intelligent teachers that can control his/her emotions, also teach students skills to regulate their emotions in order to make the teaching and learning process seamless. A teacher that can regulate his/her emotions is able to modify students' behavioral problems effectively. Emotionally intelligent teachers are aware of likely problems that can interfere with learning and proactive measures are usually taken to modify such undesirable behavior in -order to achieve quality education hence, teachers training institutions need to develop teachers that are academically and emotionally stable.

Empathy is an essential component of emotional intelligence. In this era, where there is emphasis on inclusive education, there is need to train teachers that understand the relevance of empathy in learning and also practice it. Carl Rogers in Uzoeshi and Iwundu (2002) defined empathy as the act of perceiving an individual's problem as his or hers. An emotionally intelligent teacher empathizes with students; empathy requires the teacher to examine issues based on students' perspective, being non-judgmental, understanding their feelings and communicate with the students. Empathy produces quality and effective teaching practices. This is individual differences among students in the classroom, this situation place responsibility on teachers to empathize and treat each student as a unique individual with potentials that need to be maximized. It is questionable how teachers can deal with individual differences among students without being empathic teachers. An empathetic teacher is expected to convey feelings of understanding, by putting him or herself in the person's shoe while consistently responding to the student's needs, there are individual differences among students in the classroom, instead of being critical and judgmental an emotionally intelligent teacher communicate understanding of student's perspective, unconditional acceptance and respond to students needs compassionately. Effective teaching and learning process requires a teacher who can understand and interpret students feelings and emotions, empathy shown by a teacher makes an impressionable remark. When students are respected and unconditionally accepted, it boosts their self-esteem which in turn motivates them to achieve their maximum potentials and become useful citizens of the society. The role of motivation in providing quality education cannot be overemphasized. 
Motivation is described as the energetic propeller which propels man toward achievement of a goal. Uzoeshi and Iwundu (2012) defined motivation as a drive or push which energizes an individual towards the accomplishment of a goal or task. Emotionally intelligent teachers are motivated towards accomplishment of their goals, they set realistic and achievable goals for their students which ginger high level of academic achievement, curiosity, creativity and ultimately produce high quality education; motivation is a pre-requisite for quality education, therefore teacher training institutions need to stress on the need to acquaint teachers with emotional intelligence skills. Coleman identified four elements of motivation they are drive to achieve, commitment to goals, readiness and resilience all these could be made possible through development of emotionally intelligent teachers that are intrinsically and extrinsically motivated to provide quality education for the leaners.

A teacher with knowledge of emotional intelligence assists students to develop social skills and boost that interpersonal relationship in the classroom. In the same vein, emotionally intelligent teachers encourage students to develop high self- concept and self-confidence. The type of relationship students have with their teachers and peers is a predictor of academic achievement. To this effect, education should not be limited to cognitive ability alone, emotional intelligence should be given desired consideration. Irrespective of what the curriculum content is, if students and teachers lack emotional intelligence competencies, students will not be behaviorally disposed to learn. Given, the numerous benefits of emotional intelligence, it is imperative for teachers training institutions to place priority on emotional intelligence of teachers.

\section{CONCLUSION}

Conclusively, Emotional intelligence is an essential part of professional development for quality education, it is Difficult for a learner who is emotionally destabilized to benefit from learning experiences. In the same vein, teachers need to be emotionally intelligent to cope with all the various emotions in a classroom. In order to provide quality education, there is need for teachers training institutions to develop programs that will equip pre-service teachers with emotional intelligent skills, this will go a long way in strengthening the educational system for quality education.

\section{8.} RECOMMENDATIONS

The following recommendations were made;

1. Seminars and conferences should be organized to enlighten the general public about the significance of emotional intelligence on student's efficacy, motivation and academic achievement.

2. Teachers preparation institutions should equip pre- service teachers with emotional intelligence skills in order, to develop teachers that are socially, academically and emotionally balanced.

3. Parents and guardians should be well acquainted with emotional intelligence skills in order to train children across the various stages of development.

4. Emotional intelligence programs should be infused in teacher preparatory curriculum this will enable teachers to manage their emotions and that of others.

5. Training and re-training of teachers on emotional intelligence skill should be made mandatory in order to update teachers about available programs.

\section{REFERENCES}

1. Akinnade, C. M. (2008). Reasons for second wife among men as perceived by people in Oyo East local government area of Oyo state. Unpublished Masters' Thesis, University of Lagos.

2. Ezeonwuka, C. \& Okanume-Onah, A.V. Quality and Access to education in Nigeria the Journey so far. Onitsha; Global Academic Resources.

3. Fafunwa, A.B. (2004). History of education in Nigeria. Ibadan: Educational publisher limited.

4. Gold, Y. \& E. Roth (1993). Teachers Managing Stress and Preventing Burnout: The Professional Health Solution. Washington: D.C Falmer Press.

5. Gross, J. J. (2002). Emotional Regulation, Affective, Cognitive and Social consequences psychophysiology. 39, $281-291$

6. Goleman, D. (1998). Working with Emotional Intelligence. New York: Barhembooks.

7. Mayer, J.D. Salovey, P. \& Caruso, D. (2000). Module of Emotional Intelligence: Handbook of Intelligence. New York: Cambridge University Press.

8. Matthews, G. (2014). Influence of Pupil-teacher attachment Patterns on Academic Achievement \& Socio-emotional wellbeing. An Unpublished thesis, University of Port-Harcourt.

9. Maple, E.E. (2011). Quality Promotion in Nigerian Educational System; Issues and challenges in Nigerian education $21^{\text {st }}$ Century. Onitsha: West and Solomon Publishing, Vol 2, pp378 -381.

10. Nwaldo, E.N. (2015). Teachers' Role in the Transformation Agenda in Nigeria: the pointer Monday, march 9, p.17. 
11. Oyekan, S.O. (2006). Foundations of Teacher Education. Ibadan: Ben Quality Prints.

12. Richardson, B.G. (2001). Working with challenging youths; lessons learned along the way. Philadelphia: Brunner routeledge.

13. Sulton, R.E. (2004). Emotion Regulation Goals and Strategies of Teachers, Social Psychology of Education 7, 379 - 398.

14. Singh, D. (2003). Emotional Intelligence at work: A professional Guide. New Delhi: Sage Publication. 